\title{
Serum Insulin-Like Growth Factor Binding Protein 7 for Esophagogastric Junction Adenocarcinoma Diagnosis
}

\author{
Gao-Ming Zhang ${ }^{1}$, Guo-Ming Zhang ${ }^{1}$, and Jian-Hua Zhang ${ }^{2}$ \\ ${ }^{1}$ Department of Laboratory Medicine, Shuyang People's Hospital, The Affiliated Shuyang Hospital of Xuzhou Medical University, Shuyang, and \\ ${ }^{2}$ Jiangsu College of Nursing, Huai'an, China
}

\section{To the Editor:}

Liu et al. ${ }^{1}$ published an article entitled "Serum insulin-like growth factor binding protein 7 as a potential biomarker in the diagnosis and prognosis of esophagogastric junction adenocarcinoma." To evaluate the serum insulin-like growth factor binding protein 7 (IGFBP7) reflects for the diagnosis of esophagogastric junction adenocarcinoma (EJA), the investigators collected 120 EJA and 80 healthy controls. Serum IGFBP7 was determined using enzyme-linked immunosorbent assay. They found that serum IGFBP7 was significantly higher in EJA than healthy controls and the area under receiver operating characteristic curve is 0.794 . Therefore, they concluded that serum IGFBP7 is used for EJA diagnosis.

We applaud the authors' attempt to find a noninvasive biomarker for EJA. However, we would like to raise some questions for the authors. First, when the author selected 80 healthy individuals as the healthy control, did the authors consider the problem of morbidity or source of the healthy control? However, the healthy control of this study should be insufficient, there will be a low-estimate of specificity and vice versa. ${ }^{2}$ The healthy control of this study should be all non-cancers in the process of diagnosis and treatment came from the populations of the different standard exclusion. Second, this study consists of two independent cohorts from different population (healthy control and EJA), thus, this belongs to a typical two-gate design study. ${ }^{2}$ Because of the controls and cases come from different individuals. From above questions for judging, these conclusions seem doubtful in this study. Obviously, this study design is a two- gate design study using healthy controls, and a two-gate design study with alternative diagnosis.

In summary, the study provides a candidate biomarker about serum IGFBP7 for EJA diagnosis. However, they need a well-designed study for further verify the reliability of the conclusions. We recommend using a single-gate design study for diagnostic study.

\section{CONFLICTS OF INTEREST}

No potential conflict of interest relevant to this article was reported.

\section{ORCID}

Gao-Ming Zhang https://orcid.org/0000-0002-6234-9414 Guo-Ming Zhang https://orcid.org/0000-0003-0662-1302

Jian-Hua Zhang https://orcid.org/0000-0003-2342-6883

\section{REFERENCES}

1. Liu CT, Xu YW, Guo H, et al. Serum insulin-like growth factor binding protein 7 as a potential biomarker in the diagnosis and prognosis of esophagogastric junction adenocarcinoma. Gut Liver. Epub 2019 Dec 13. https://doi.org/10.5009/gnl19135.

2. Zhang GM, Zhang GM, Gu B. Serum transforming growth factor beta1 level for knee osteoarthritis diagnosis. Clin Chim Acta 2017;474:136.

\footnotetext{
Correspondence to: Guo-Ming Zhang

Department of Laboratory Medicine, Shuyang People's Hospital, The Affiliated Shuyang Hospital of Xuzhou Medical University, Jiangsu, Shuyang 223600, China

Tel: +86-52787790051, Fax: +86-52787790051, E-mail: gm@xzhmu.edu.cn

Received on December 16, 2019. Accepted on February 15, 2020. Published online March 27, 2020.

pISSN 1976-2283 eISSN 2005-1212 https://doi.org/10.5009/gnl19423

@ This is an Open Access article distributed under the terms of the Creative Commons Attribution Non-Commercial License (http://creativecommons.org/licenses/by-nc/4.0) which permits unrestricted non-commercial use, distribution, and reproduction in any medium, provided the original work is properly cited.
} 